\title{
Effect of consuming endophyte-infected fescue seed on transcript abundance in the mammary gland of lactating and dry cows, as assessed by RNA sequencing
}

\author{
Anthony V. Capuco, ${ }^{*}$ Derek Bickhart, $†$ Congjun Li, ${ }^{*}$ Christina M. Evock-Clover, ${ }^{*}$ Ratan K. Choudhary, $\ddagger^{1}$ \\ Paolo Grossi,§ Giuseppe Bertoni,\# Erminio Trevisi,\# Glen E. Aiken,II Kyle R. McLeod,ף \\ and Ransom L. Baldwin VI ${ }^{* 2}$ \\ *Animal Genomics and Improvement Laboratory, USDA-ARS, Beltsville, MD 20705 \\ †Cell Wall Biology and Utilization Laboratory, USDA-ARS, Madison, WI 53726 \\ ‡Department of Animal and Avian Sciences, University of Maryland, College Park 20742 \\ §Società Italiana Veterinaria Agricola Milano S.p.A., 26841 Casalpusterlengo (LO), Italy \\ \#lstituto di Zootecnica, Università Cattolica del Sacro Cuore, 29100 Piacenza, Italy \\ IIForage-Animal Production Research Unit, USDA-ARS, Lexington, KY 40506 \\ TDepartment of Animal Sciences, University of Kentucky, Lexington 40546
}

\begin{abstract}
Ergot alkaloids in endophyte-infected grasses inhibit prolactin secretion and reduce milk production in lactating cows. However, we previously showed that prepartum consumption of infected seed throughout the dry period did not inhibit subsequent milk production and prior exposure to bromocriptine (ergot peptide) actually increased production in the next lactation. To identify changes in the transcriptome and molecular pathways mediating the mammary gland's response to ergot alkaloids in the diet, RNA sequencing (RNAseq) was performed on mammary tissues obtained from 22 multiparous Holstein cows exposed to 1 of 3 treatments. Starting at $90 \pm 4 \mathrm{~d}$ prepartum, cows were fed endophyte-free fescue seed (control; CON), endophyte-free fescue seed plus $3 \times /$ wk subcutaneous injections of bromocriptine (BROMO; $0.1 \mathrm{mg} / \mathrm{kg}$ of $\mathrm{BW}$ ), or endophyte-infected fescue seed (INF) as $10 \%$ of the diet. Cows were dried off $60 \pm 2 \mathrm{~d}$ prepartum. Mammary biopsies from 4 (BROMO, INF) or 5 $(\mathrm{CON})$ cows/treatment at each of the 3 phases were obtained: $7 \mathrm{~d}$ before dry off during the initial lactation (L1), mid-dry period (D), and $10 \mathrm{~d}$ postpartum (L2). Although tissue from the same cow was preferentially used at 3 phases (L1, D, L2), tissue from additional cows were used to as necessary to provide RNA of sufficient quality. Individual samples were used to generate individual RNA-seq libraries. Normalized reads of

\footnotetext{
Received March 12, 2018.

Accepted June 27, 2018

${ }^{1}$ Current address: School of Animal Biotechnology, GADVASU,

${ }^{2}$ Corresponding author: ransom.baldwin@ars.usda.gov
} Ludhiana, Punjab 141004, India.
\end{abstract}

the RNA-seq data were organized into technical and biological replicates before processing with the RSEM software package. Each lactation phase was processed separately and genes that differed between any of 3 treatments were identified. A large proportion of genes differentially expressed in at least 1 treatment $(\mathrm{n}=$ 866) were found to be similarly expressed in BROMO and INF treatments, but differentially expressed from CON ( $\mathrm{n}=575$, total for 3 phases). Of genes differentially expressed compared with CON, 104 genes were common to the L1 and L2 phases. Consistent with the production findings, networks most affected by treatments in L1 and L2 included lipid metabolism, small molecule biochemistry, and molecular transport, whereas networks related more to developmental and cellular functions and maintenance were evident during D phase. Similar patterns of expression in BROMO and INF during late and early lactation suggest involvement of similar cell signaling pathways or mechanisms of action for BROMO and INF and the importance of prolactin messaging pathways.

Key words: ergot alkaloids, RNA sequencing, prolactin, milk yield

\section{INTRODUCTION}

Tall fescue is a common pasture grass throughout much of the United States due to its persistence and drought tolerance. However, animal productivity is often reduced when animals graze on tall fescue due to ingestion of ergot alkaloids found in the fungal endophyte-infected plant (Strickland et al., 1993; Aiken and Strickland, 2013). Although numerous studies have documented a correlation between consumption of endophyte-infected fescue and decreased milk production (Peters et al., 1992; Brown et al., 1993; Aiken and 
Strickland, 2013), this represents only a portion of its potential effect. Little is known regarding the effect of ergot alkaloids on mammary growth and development. Using a synthetic ergot alkaloid that markedly inhibits prolactin (PRL) secretion, we previously demonstrated that PRL is important for the final stage of mammary differentiation that occurs during the periparturient period, resulting in decreased milk yield during the first $10 \mathrm{~d}$ after parturition when the experiment was terminated (Akers et al., 1981a,b). Conversely, feeding endophyte-infected tall fescue for approximately 1 mo before calving reduced plasma PRL concentrations but did not significantly affect milk production during the initial 10 wk after calving (Bernard et al., 1993). Consumption of ergot alkaloids was not assessed in the latter study and thus warranted additional study. We subsequently demonstrated that consumption of endophyte-infected fescue seed during the dry period did not significantly affect parameters of mammary growth nor decrease milk production in the subsequent lactation (Baldwin et al., 2016).

Elucidation of the cellular and molecular mechanisms by which ingestion of endophyte-infected grasses impairs milk production and mammary gland function should reveal methods to offset or alleviate these effects, and thus enhance animal productivity and health. We initially hypothesized that consumption of endophyte-infected fescue during the dry period would inhibit mammary differentiation, and possibly mammary growth, primarily due to a disruption of PRL stimulation. Because bromocriptine is a dopamine agonist that inhibits the secretion of PRL by the pituitary gland and decreases circulating concentrations of PRL (Fitzgerald and Cunningham, 1982), we included bromocriptine treatment as a positive control. The objective of our study was to determine the effect of consuming endophyte-infected fescue during late lactation and the dry period on mammary development and productivity in the next lactation. To ensure that treatment encompassed the final stage of mammary differentiation, treatment was continued until d 10 of the subsequent lactation, at which point it was discontinued. We concluded that although feeding endophyte-infected fescue during lactation decreased milk production, its consumption during the dry period did not affect milk yield in the following lactation after consumption of endophyte-infected fescue was terminated (Baldwin et al., 2016). In the current manuscript we used RNA sequencing (RNA-seq) to evaluate the influence of bromocriptine treatment and consumption of endophyte-infected fescue seed on gene expression in mammary tissue during lactation and the dry period, thereby revealing control mechanisms mediating these effects.

\section{MATERIALS AND METHODS}

\section{Experimental Scheme}

As described previously (Baldwin et al., 2016), 24 multiparous Holstein cows from the Beltsville (Maryland) Agricultural Research Center Dairy were used in this investigation. Twenty-two of these 24 cows provided mammary tissue for the analysis of gene expression described in the current manuscript. Cows were assigned to 1 of 3 treatments: (1) negative control $(\mathbf{C O N} ; \mathrm{n}=9)$, fed a diet containing K32 tall fescue seed, certified endophyte-free, added as $10 \%$ of the ration as fed; (2) positive control (BROMO; $\mathrm{n}=7$ ), fed a diet containing K32 fescue seed and additionally received subcutaneous injections of the dopamine agonist, bromocriptine (3 times/wk; $13.6 \mathrm{mg} / \mathrm{mL}$ in $90 \%$ ethanol; $0.1 \mathrm{mg} / \mathrm{kg}$ of BW), to inhibit PRL secretion; or (3) endophyte-infected fescue group (INF; $\mathrm{n}=8$ ), fed a diet containing K31 tall fescue seed, infected with endophyte (Epichloë coenophiala), added as $10 \%$ of the ration. Treatments were imposed from $90 \pm 4 \mathrm{~d}$ before expected calving (cows were dried off $60 \pm 2 \mathrm{~d}$ before expected calving) until $10 \mathrm{~d}$ postpartum. Cows were housed in tiestalls for the duration of the study, with daily exercise of at least $3 \mathrm{~h}$. Several days before expected calving cows were moved to a maternity stall. Throughout the experiment, lighting was maintained at $16 \mathrm{~h}$ of light, $8 \mathrm{~h}$ of dark.

Endophyte-infected and noninfected fescue seed were purchased as single lots from a commercial seed supplier (Turner Seed Inc., Winchester, KY). Samples of each lot were collected using a bag trier (\#236; Seedboro, Chicago, IL) and a minimum of 10 bags were sampled per lot. Samples were subsequently composited within lot, ground through a 1-mm screen (model 3 Wiley Mill; Arthur H. Thomas Co., Philadelphia, PA), and analyzed for ergovaline and ergovalanine content by HPLC fluorescence using the procedure described by Yates and Powell (1988) as modified by Carter et al. (2010).

The treatment scheme, dry period, biopsy schedule (described below), and collection of milking records are illustrated in Figure 1. Additional experimental details are provided in our previous publication (Baldwin et al., 2016). All procedures involving animals were approved by the Beltsville Agricultural Research Center Animal Care and Use Committee.

\section{Tissues and RNA-sequencing}

Biopsy. Mammary tissue $(0.5-1 \mathrm{~g})$ was obtained via biopsy the week before drying off $(\mathbf{L} 1 ; 67 \pm 2 \mathrm{~d}$ before expected parturition), during the dry period 
(D; $32 \pm 2 \mathrm{~d}$ before expected parturition), and $10 \mathrm{~d}$ postpartum $(\mathbf{L} 2 ; \pm 1 \mathrm{~d})$. Rear quarters were biopsied in all cases; the 10-d sample was obtained from the same quarter as the -67-d sample, but at a different location within the gland. Tissues biopsies were obtained using the biopsy tool and methodology previously described (Farr et al., 1996; Hale et al., 2003), but additionally inserting a sterile teat cannula during the biopsy to promote drainage of blood during the procedure. Tissue was immediately snap-frozen in liquid nitrogen for gene expression analysis by RNA-seq. The SCC at time of biopsy did not differ between treatments (Baldwin et al., 2016). An outline of processing for RNA-seq evaluation is provided in Figure 2.

$\boldsymbol{R N A}$ Isolation. Total RNA was purified using an RNeasy Mini kit (Qiagen, Valenica, CA). Residual genomic DNA in the total RNA samples was removed by incubation with 4 to 10 units of DNase I per 100 $\mu \mathrm{g}$ total RNA (Ambion, Austin, TX) at $37^{\circ} \mathrm{C}$ for 30 min. The RNA integrity was verified using the Bioanalyzer 1000 (Agilent Technologies, Palo Alto, CA) and the concentration was determined using a NanoDrop ND-1000 spectrophotometer (NanoDrop Technologies, Rockland, DE). Poly-A containing mRNA was isolated from total RNA using the Oligotex Direct mRNA Mini Kit (Qiagen) using the manufacturer's protocol (https://www.qiagen.com/us/resources/resourcedetail ?id=f9fa1d98-d54d-47e7-a20b-8b0cb8975009\&lang = en). The mRNA was analyzed using the Bioanalyzer 1000 and NanoDrop spectrophotometer. Total RNA and mRNA were of high quality (Table 1). Although a repeated-measures statistical design was not employed, tissues from mammary biopsies of the same cow were preferentially used to provide RNA for the 3 phases (L1, D, L2) in a given replicate. However, to optimize the quality of RNA for RNA-Seq, RNA obtained from biopsy of another cow in the same treatment was frequently used for a given replicate. Ultimately, 3 cows provided RNA for L1, D, and L2. In the remaining instances, a single cow provided RNA for 2 phases and another cow provided RNA for the remaining phase. Thirty-nine mammary samples from 22 cows were processed and subjected to RNA-Seq,

RNA Library Construction. Following mRNA purification, samples were processed by Expression Analysis (Durham, NC) using the mRNA-Seq sample prep kit (Illumina Inc., San Diego, CA). Biopsy samples from each treatment group at the 3 phases of the lactation cycle (L1, D, and L2) were used to generate individual RNA-seq libraries. The mRNA for each sample was fragmented and used in first-strand cDNA synthesis employing reverse transcriptase and random primers. Second-strand cDNA synthesis was then accomplished using DNA Polymerase I and RNaseH. The ends of the cDNA fragments were then repaired, a single "A" base added, and then the resulting fragments

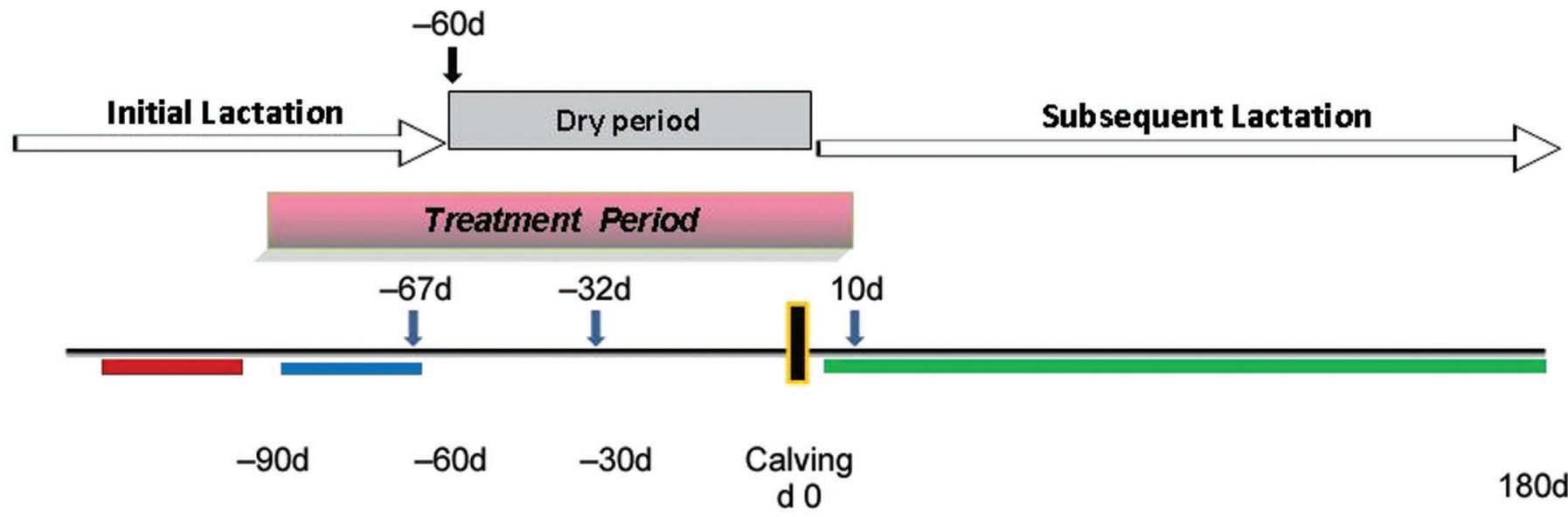

\section{$\downarrow$ Mammary biopsies: $\mathrm{d}-67,-32$ and $+10=$ Milk record (30 d) prior to treatment, initial lactation $\downarrow$ Dry off, $-60 \mathrm{~d}$ Milk record (30 d) after treatment, initial lactation \\ - Milk record next (subsequent) lactation}

Figure 1. Experimental treatment scheme and biopsy schedule. Timeline represents days relative to expected calving (prepartum) or actual calving (postpartum). Figure reprinted from Baldwin et al. (2016) with permission. Color version available online. 


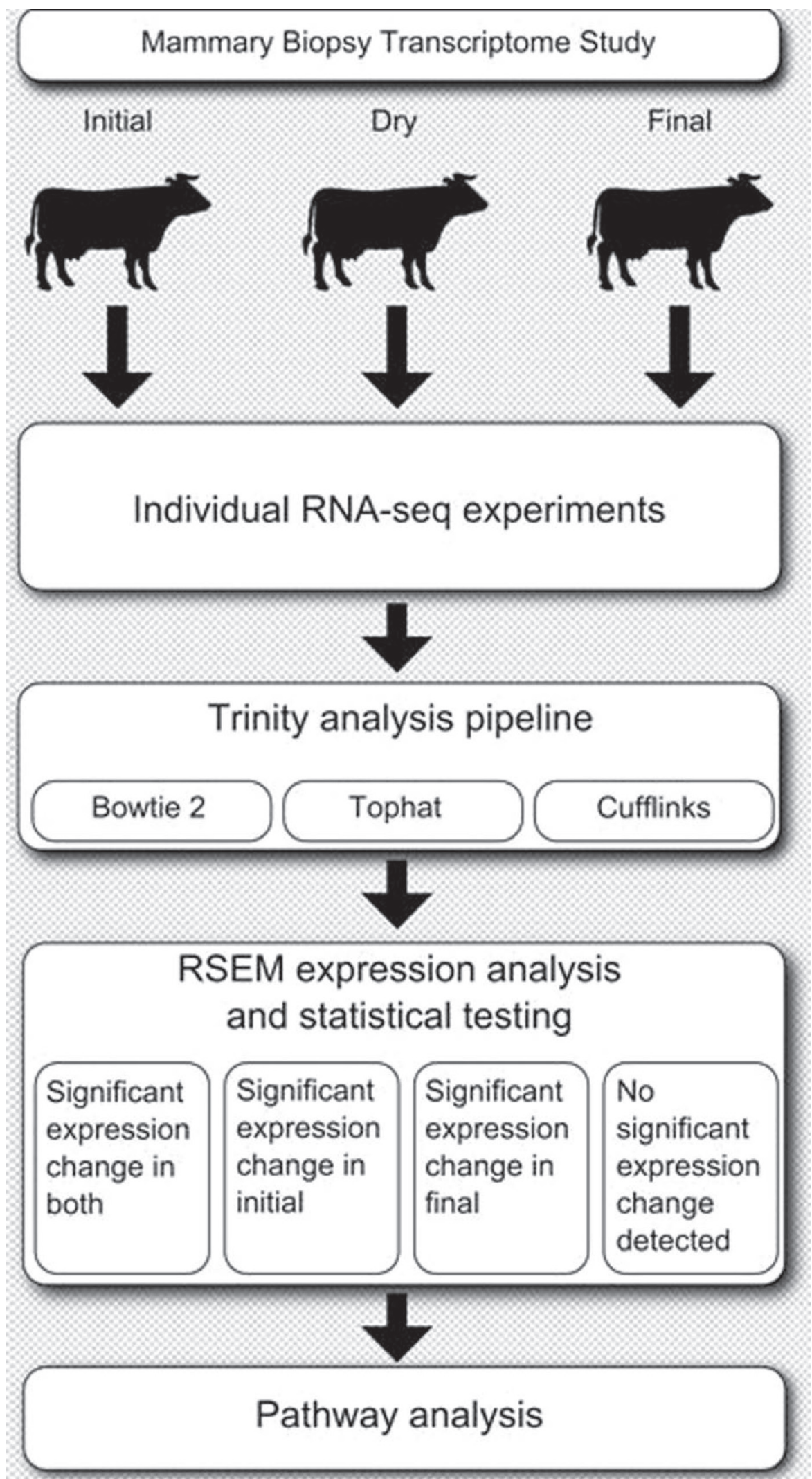

Figure 2. Outline of RNA sequencing (RNA-seq) evaluation. $\mathrm{B}=$ bromocriptine treatment; $\mathrm{I}=$ endophyte-infected fescue treatment; $\mathrm{C}=$ control treatment; RSEM = RSEM software (version 1.2.24; Li and Dewey, 2011). 
Table 1. Quality of RNA isolated from mammary biopsies

\begin{tabular}{llccccc}
\hline & & \multicolumn{3}{c}{ Treatment $^{1}$} \\
Stage $^{2}$ & RIN $^{3}$ & CON & BROMO & INF & Mean & SEM \\
\hline Initial lactation & Mean & 7.30 & 7.43 & 6.90 & 7.22 & 0.15 \\
\multirow{3}{*}{ Dry } & SEM & 0.19 & 0.34 & 0.26 & \multirow{2}{*}{7.29} & 0.09 \\
\multirow{2}{*}{ Subsequent lactation } & Mean & 7.24 & 7.35 & 7.30 & & \\
& SEM & 0.16 & 0.13 & 0.20 & \multirow{2}{*}{6.25} & 0.26 \\
& Mean & 6.00 & 6.70 & 6.13 & & \\
& SEM & 0.45 & 0.25 & 0.60 & & \\
& Mean & 6.85 & 7.16 & 6.78 & & \\
\hline
\end{tabular}

${ }^{1}$ Stages were: initial lactation, dry period and the subsequent lactation (10 DIM).

${ }^{2} \mathrm{CON}=$ control; INF $=$ infected-fescue seed; BROMO = bromocriptine.

${ }^{3} \mathrm{RIN}=$ RNA integrity number. RNA integrity was equivalent across treatment $(P>0.05)$, but RNA isolated from samples in subsequent lactation was of lower quality $(P<0.05)$.

ligated to adapters. The products were then purified and amplified by PCR to create the cDNA library for each sample.

$\boldsymbol{R} N \boldsymbol{A}-\mathrm{seq}$ and Data Processing. The RNA-seq was performed commercially by Expression Analysis (Durham, NC), using next-generation sequencing (Illumina Inc.). Each biological and technical replicate RNA sample was sequenced to a minimum read count of 18 million read pairs, with the average coverage consisting of 25.6 million read pairs. For purpose of this analysis, normalized read counts generated by the EBseq $\mathrm{R}$ package (Leng and Kendziorski, 2015) were used as the expression values of Ensembl (UMD3.1 version 71 annotation; https://uswest.ensembl.org/Bos_taurus / Info/Annotation) annotated genes. Normalized read counts were organized into technical and biological replicates before processing with the RSEM software package v1.2.24 (Li and Dewey, 2011). Each lactation phase was processed separately with the "rsem-run-ebseq" pipeline, and genes that differed between any of 3 treatments were identified from program output. Genes with a posterior probability of differential expression greater than $90 \%$ were considered to be differentially expressed in at least 1 treatment group. Further details of the methods used and command line arguments are available online (https://github.com/njdbickhart/labnotes/ blob/master/project_notes/gene_expression_projects / Notes_20150514_dbick_fescue_rnaseq_de.md).

\section{Ingenuity Pathway Analysis}

Pathways Analysis. Ingenuity Pathway Analysis (IPA; Qiagen) was used to analyze RNA-seq data sets according to previously described methods (Li et al., 2007; Wu et al., 2012; Krämer et al., 2014). The IPA is a powerful analysis and search tool that uncovers the significance of RNA-seq data and identifies new targets or candidate biomarkers within the context of biological systems. All differentially expressed genes in the data sets were uploaded into the IPA software; IPA enabled us to identify the biological mechanisms, pathways, and functions most relevant to the experimental data sets or differentially expressed genes.

Canonical Pathway Analysis of Data Sets. Canonical pathway analysis identifies the most significant canonical pathways in the data set from the IPA library of canonical pathways database. Genes from the data set that were related to a canonical pathway in the Ingenuity Pathways Knowledge Base were considered for the analysis. Two measurements were evaluated between the data sets and the Ingenuity Pathways Knowledge Base for the significance between the data set and the canonical pathway. The first is a ratio of the number of genes from the data set that map to the pathway divided by the total number of genes that map to the canonical pathway. The second, Fisher's exact test, was used to calculate a $P$-value that determines the probability of an association between the genes in the data set and the canonical pathway.

Pathway Analysis and network generation. The data sets containing gene identifiers and corresponding expression values were uploaded into the IPA application. Each gene identifier was mapped to its corresponding gene object in the Ingenuity Pathways Knowledge Base. These genes, called focus genes, were overlaid onto a global molecular network developed from information contained in the Ingenuity Pathways Knowledge Base. Networks of these focus genes were then algorithmically generated based on their connectivity.

Network Generation. All data sets containing differentially expressed gene identifiers and corresponding expression values were uploaded into in the IPA application. Each identifier was mapped to its corresponding object in Ingenuity's Knowledge Base. These genes, called network-eligible molecules, were overlaid onto a 
global molecular network developed from information contained in Ingenuity's Knowledge Base. Networks of network-eligible molecules were then algorithmically generated based on their connectivity.

Functional Analysis of Data Sets. The functional analysis identified the biological functions or diseases that were most significantly applicable to the data set. Differentially expressed genes in the data set that were associated with biological functions or diseases in Ingenuity's Knowledge Base were considered for the analysis. Right-tailed Fisher's exact test was used to calculate a $P$-value determining the probability that each biological function or disease assigned to that data set is not due to chance alone.

\section{RESULTS AND DISCUSSION}

The quality of RNA-seq data that were obtained from this experiment was very good. Tissue from mammary biopsies yielded high-quality RNA with an average RNA integrity number (RIN) of $6.92 \pm 0.13$ (mean \pm SEM). Treatment did not affect RIN, but RNA quality was significantly lower in samples collected on d 10 of the subsequent lactation $(P<0.05$; Table 1$)$. Nonetheless, the amplified cDNA and subsequent sequences that were generated were of high quality for all samples. The average size of labeled cDNA was $277 \pm 0.48 \mathrm{bp}$, with no difference among treatments or physiological stage $(P>0.05)$. Additionally, quantile-quantile plots showed reasonable adherence to a normal distribution, but with a right skew in the upper tail of the distribution that is indicative of expression fold-change differences (data not shown).

A listing of differentially expressed genes is provided as a supplemental table (Supplemental Table S1; https: //doi.org/10.3168/jds.2018-14735). A large proportion of genes considered to be differentially expressed in at least 1 treatment $(\mathrm{n}=866)$ were found to be similarly expressed in BROMO and INF treatments, but differentially expressed from CON $(\mathrm{n}=575$, total for all 3 phases). When phases were compared, 104 genes that were differentially expressed compared with $\mathrm{CON}$ were found to be common to the L1 and L2 phases.

Evaluation of the effect of treatment on abundance of genes representative of canonical pathways led to identification of differentially expressed pathways (Figure 3). The AMPK signaling pathway was significantly enhanced by BROMO and INF treatments during the initial lactation, but not the subsequent lactation. The AMPK serves as an important sensor of cellular energy and integrator of energy signals, including hormonal signals, to meet energy demands of the cell (Viollet et al., 2010). At the time of biopsy, milk secretion was reduced in both the initial and subsequent lactations
(Baldwin et al., 2016). However, the L1 biopsy was obtained during late lactation and the L2 biopsy on d 10 of the next lactation. Although AMPK activity is regulated post-translationally, increased abundance of the gene is consistent with an increase in pathway activity, and an increase in AMPK activity is consistent with decreased biosynthetic pathways, notably fatty acid synthesis (Viollet et al., 2010), and the decreased milk yield observed in this experiment (Baldwin et al., 2016). The lack of stimulation of the AMPK pathway during L2 was likely due to the existence of a negative energy balance during early lactation. Corticotropinreleasing hormone signaling is key to regulating the stress response of the hypothalamic pituitary adrenal axis and is presumably involved in stress response in peripheral tissues, but its function in the mammary gland has not been investigated. This signaling pathway was downregulated by BROMO and INF. During the subsequent lactation, BROMO promoted canonical pathways that were related to vascular growth, immune function, cytoskeleton signaling, and cellular mobility. Surprisingly, these processes were not significantly promoted by INF during the subsequent lactation and may suggest modulation of response by additional molecules in infected seed.

An evaluation of the effect of treatment on abundance of genes involved in biological functions led to identification of differentially expressed pathways (Figure 4). Of significance was the demonstration that the effect of BROMO and INF was very similar during the 3 stages studied. During initial lactation, the treatments enhanced pathways involved in the uptake of carbohydrate and monosaccharide, whereas they decreased a variety of metabolic activities including fatty acid metabolism, molecular transport, and lipid conversion. Concomitantly, expression of genes associated with growth and development, developmental processes for mammary gland and exocrine gland, and genes influenced by feed intake were decreased, which is consistent with the reduced feed intake in BROMO and INF cows. During the subsequent lactation, BROMO and INF increased gluconeogenesis, consistent with negative energy balance at this time, and decreased pathways for other metabolic activities such as oxidation of lipid, oxidation of fatty acid metabolism, and decreased development of the mammary gland. During the dry period, BROMO and INF augmented pathways that included those involved in mammalian infection and thrombosis. Because mammary glands are susceptible to mastitis during the dry period, the former is particularly relevant to animal health. Both INF and BROMO treatments decreased pathways involving leukocyte and lymphocyte functions and may exemplify the downside to consumption of endophyte-infected 

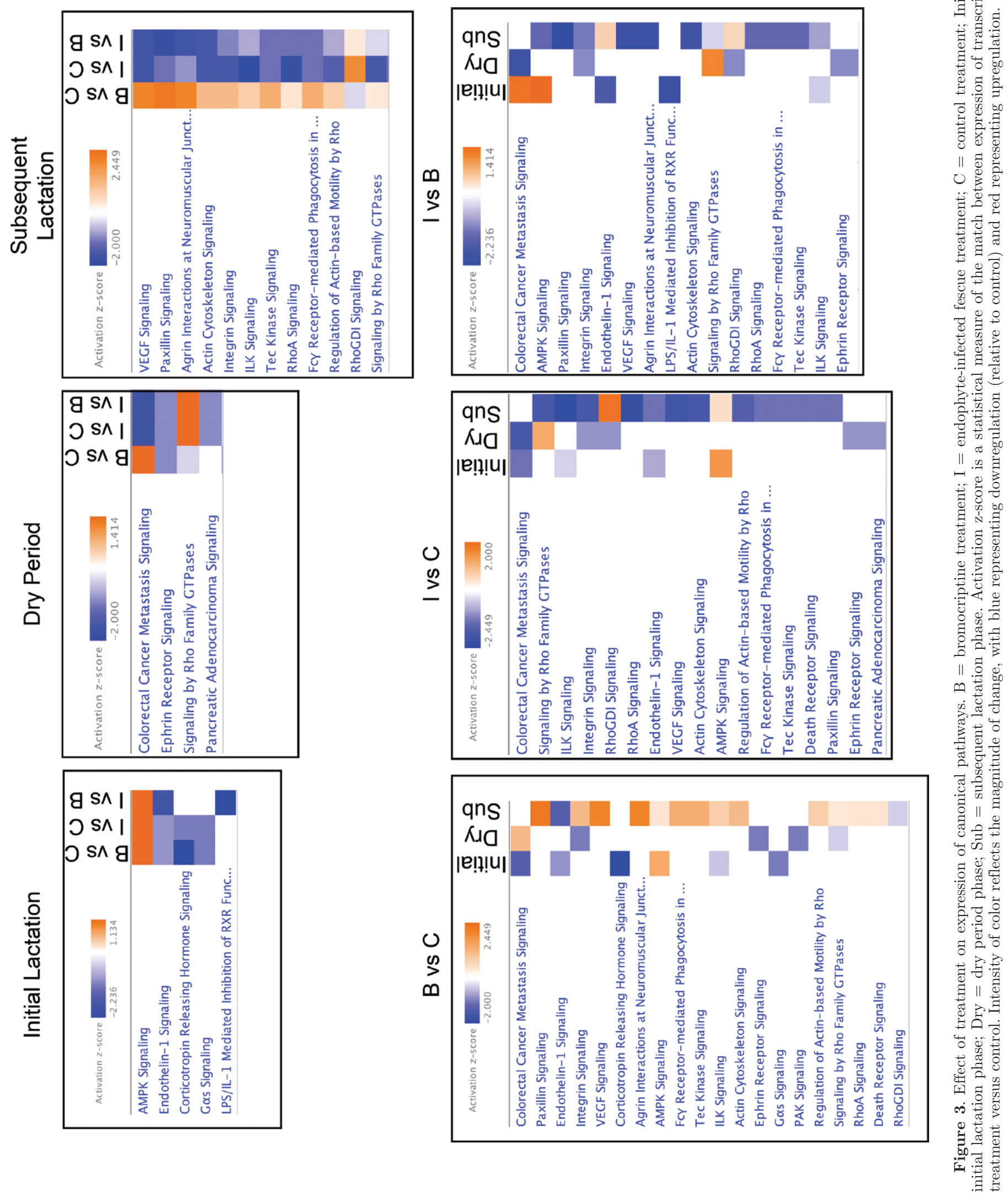
fescue grasses during the dry period. However, it seems unlikely that a greater inflammatory response in INF than BROMO cows may account for the inability of INF to increase milk yield (relative to CON) during the subsequent lactation. Indeed, the decreased activity of pathways involving leukocyte and lymphocyte function was less severely affected in INF than BROMO cows during the dry period, and these pathways were not affected during early lactation (Figure 4) and SCC during early lactation was not affected by treatment (Baldwin et al., 2016).

Ingenuity Pathway Analysis was also employed to identify significant upstream regulators (Figure 5). Here too, BROMO and INF had very similar effects by significantly affecting many of the same upstream regulators, particularly during lactation. During lactation (L1 and L2), upregulation of INSIG1 and $L P E$ and downregulation of SREBF1 and SCAP presumably regulate lipid metabolism and sterol biosynthesis, the net effect of which is likely downregulation of lipid synthesis and milk secretion as was apparent in our study. Additionally, downregulation of STAT3 likely suppresses apoptosis (Hughes and Watson, 2012) and upregulation of THRB may promote a role for thyroid hormones as promoters of lactogenesis and galactopoiesis (Capuco et al., 1995, 2008). Interestingly, during the dry period BROMO and INF promoted an increase in abundance of ESR2, an estrogen receptor that has been reported to be in very low concentration and minimal functionality in the bovine mammary gland (Connor et al., 2007). During the dry period, prominent upstream regulators that were affected by BROMO and INF were primarily those involved in immunoregulatory function, cell proliferation, and cell survival.

We hypothesized that BROMO and INF treatment would reduce circulating PRL and have similar effect on milk yield and on mammary growth during the dry period, which was observed (Baldwin et al., 2016). Both treatments reduced basal concentrations of circulating PRL, with average reductions of 84 and $87 \%$ for BROMO and INF, respectively. Similarly, the prepartum surge in PRL secretion was reduced by treatment, with average reductions of 93 and $48 \%$ for BROMO and INF, respectively. Indeed, IPA upstream analysis predicted that PRL-related functions were similarly affected in INF and BROMO cows in both the dry and lactating state (Figure 6). These functions were associated with reproduction system development and function, tissue development, cellular development, cell morphology, and cellular assembly and organization.

In addition to an effect on circulating PRL, treatments reduced feed intake. The reduction in feed intake was greater in INF cows than BROMO cows. Covariate analysis indicated that approximately $45 \%$ of the reduc- tion in milk yield due to treatment could be attributed to effects on DMI. However, because both BROMO and INF caused a reduction in DMI and milk yield, reduced feed consumption appeared to be a mechanism or pathway for reduced milk yield rather than a confounding factor (Baldwin et al., 2016). Especially considering the fact we observed no significant effects on mammary growth and development during the dry period.

Feeding cows endophyte-infected fescue seed resulted in measurable changes in the mammary gland transcriptome that were consistent with the observed changes in milk production. Bromocriptine induced transcriptome changes that were largely analogous to those induced by feeding infected seed. This suggests that the reduction in milk yield that was observed in BROMO and INF relative to CON was largely due to involvement of similar cell signaling pathways and genetic control mechanisms. Comparisons across lactation phase (L1 vs. L2) resulted in 104 genes affected in both treatments compared with control, and these genes were largely related to lipid metabolism, small molecular biochemistry, and molecular transport, perhaps reflecting changes in milk production.

An important aspect of our study that could not be addressed due to the biopsy schedule was the mechanism behind the increased milk yield following termination of BROMO treatment and the trend toward an increase following termination of INF treatment (Baldwin et al., 2016). However, the data bear a strong similarity to increased milk yield obtained when a short photoperiod before parturition (dry period treatment) is followed by a long photoperiod during lactation (Auchtung et al., 2005; Wall et al., 2005). Prolactin has been implicated as a causative factor in this response, with low PRL during the dry period sensitizing the mammary gland to a subsequent increase in PRL during lactation, which promotes an accompanying increase in milk yield (Crawford et al., 2015). Because we did not assess gene expression after termination of treatment, we were unable to test this hypothesis. However, our data provide an additional model wherein PRL is reduced during the dry period and milk yield is increased in the subsequent lactation, when PRL concentrations are restored.

\section{CONCLUSIONS}

Consistent with the milk production findings, networks most affected by treatments in L1 and L2 included lipid metabolism, small molecule biochemistry, and molecular transport, whereas networks related more to developmental and cellular functions and maintenance were evident during the $\mathrm{D}$ phase. The strong similarity in pattern of expression in BROMO and INF treatments during both late and early lactation suggests 

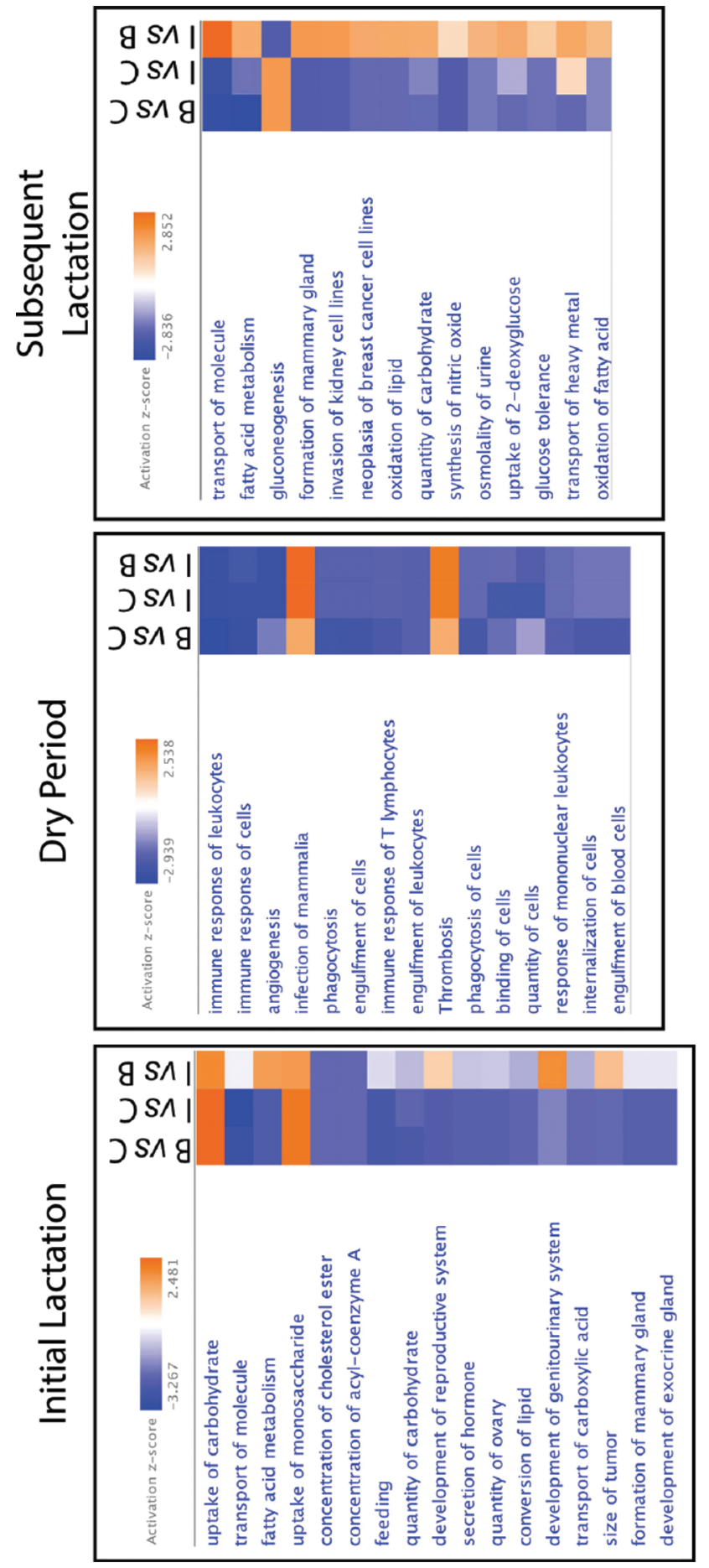
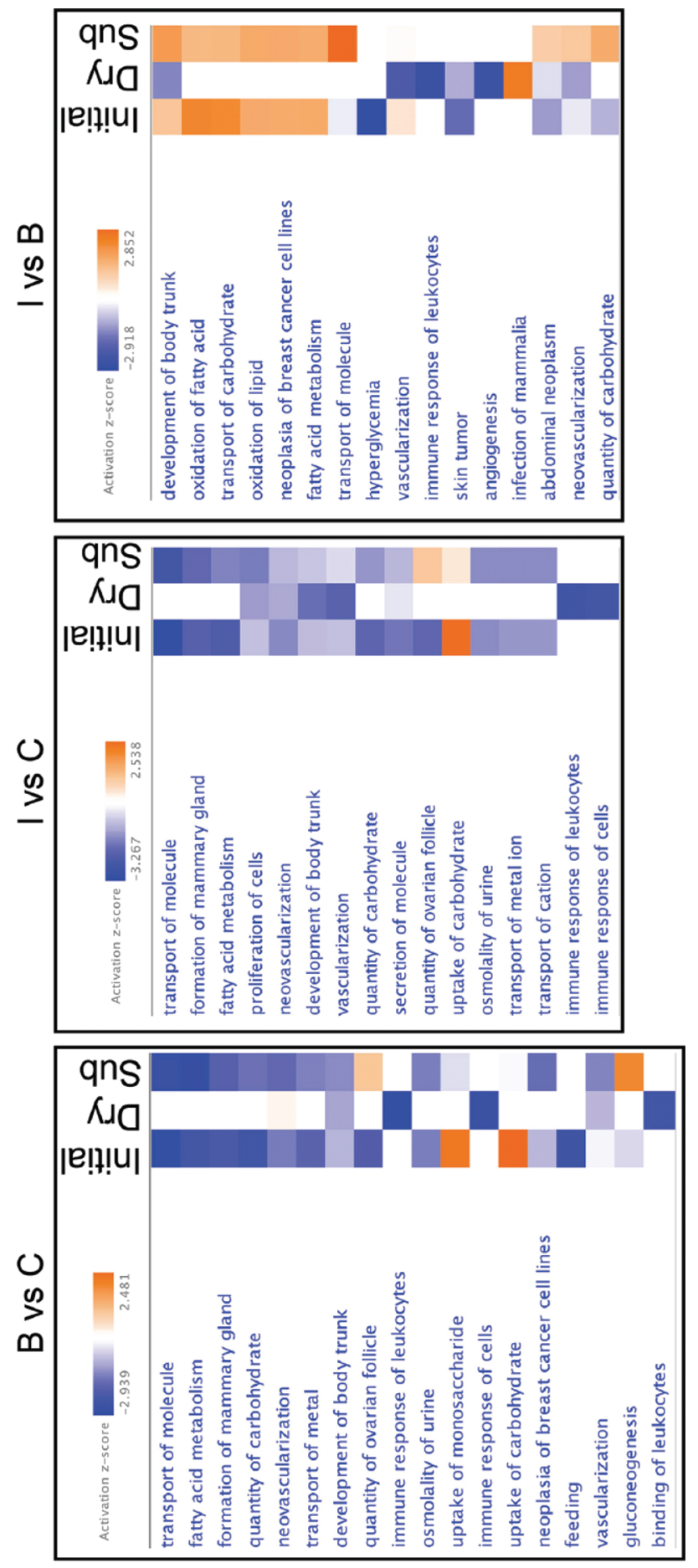

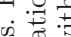

元

䒕, 苛

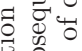

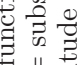

赵, 药

10 औ

웅

훙

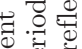

$\exists$

$\underset{0}{\overparen{0}}$

पे $\mid 1 \overrightarrow{0}$

苞言育

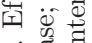

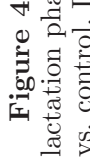


Initial Lactation

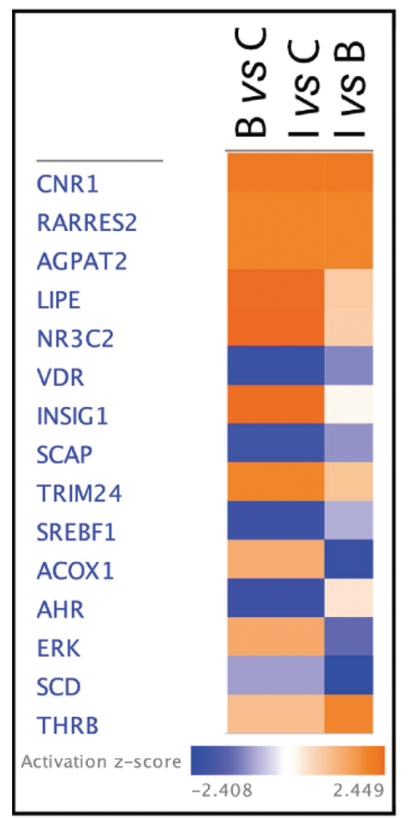

B vs C

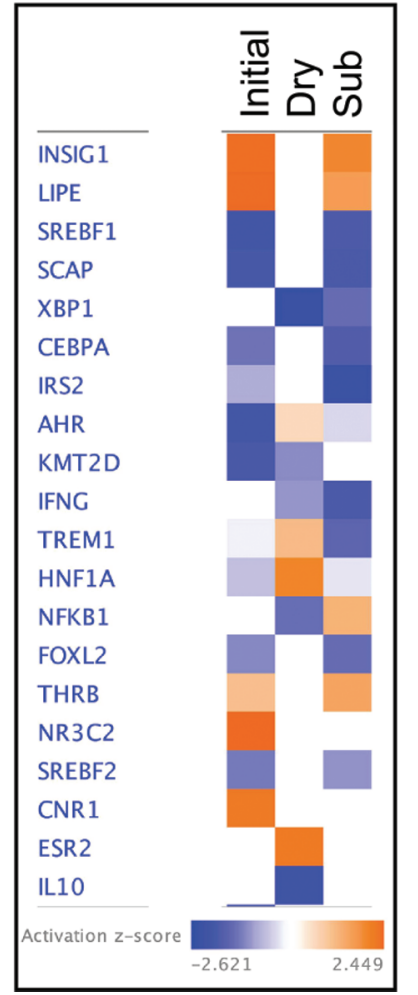

Dry Period

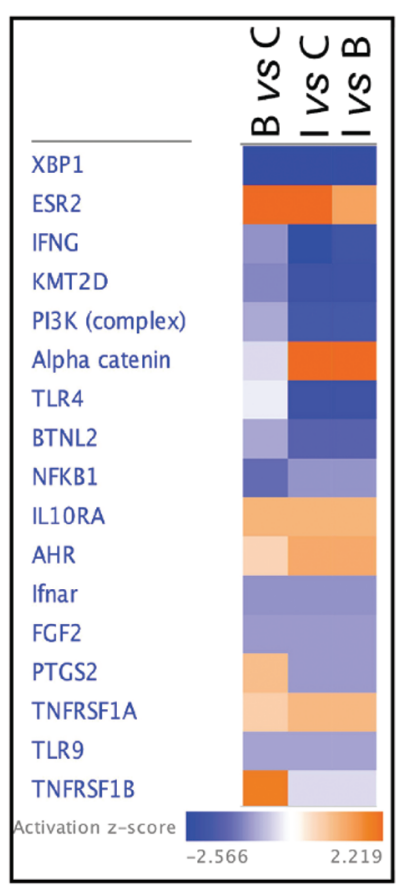

I vs $\mathrm{C}$

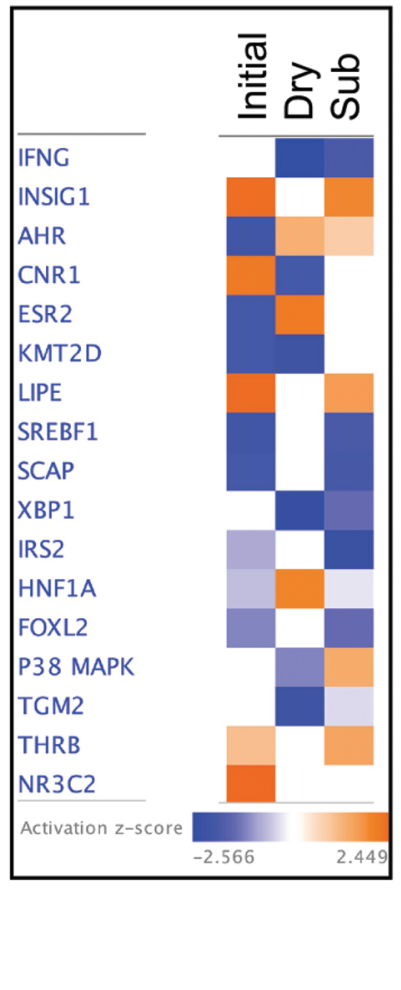

Subsequent Lactation

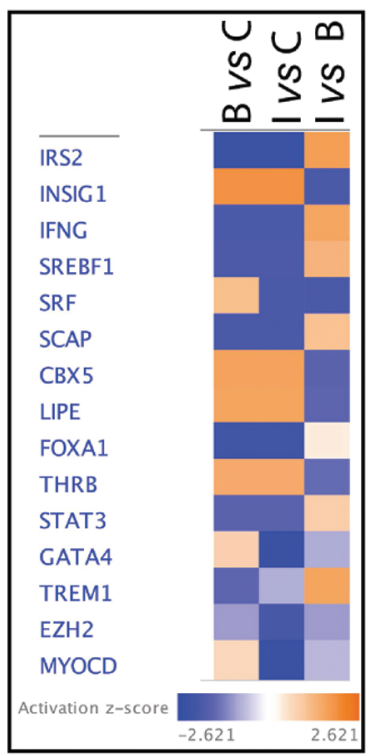

I vs $B$

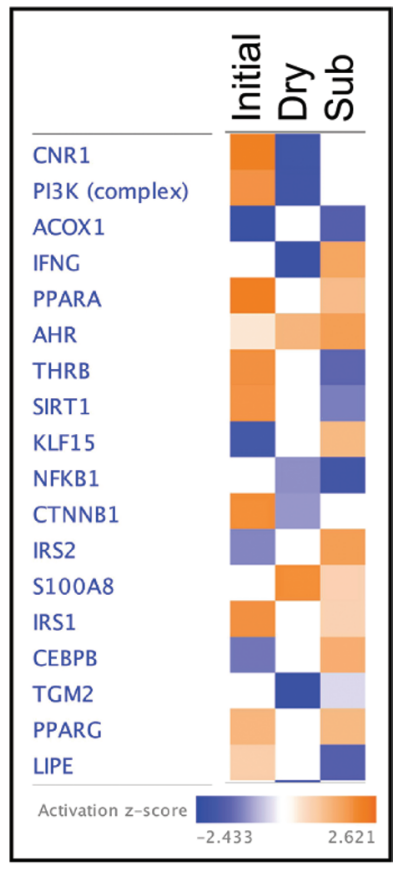

Figure 5. Effect of treatment on expression of upstream regulators. $\mathrm{B}=$ bromocriptine treatment; $\mathrm{I}=$ endophyte-infected fescue treatment $\mathrm{C}=$ control treatment; Initial $=$ initial lactation phase; Dry = dry period phase; Sub = subsequent lactation phase. Gene abbreviations used are official abbreviations the corresponding human genes. Gene abbreviations and biological functions are summarized in Appendix Table A1. Activation z-score is a statistical measure of the match between expression of regulatory and downstream transcripts in treatment vs. control. Intensity of color reflects the magnitude of change, with blue representing downregulation (relative to control) and red representing upregulation. 


\section{Dry Period}

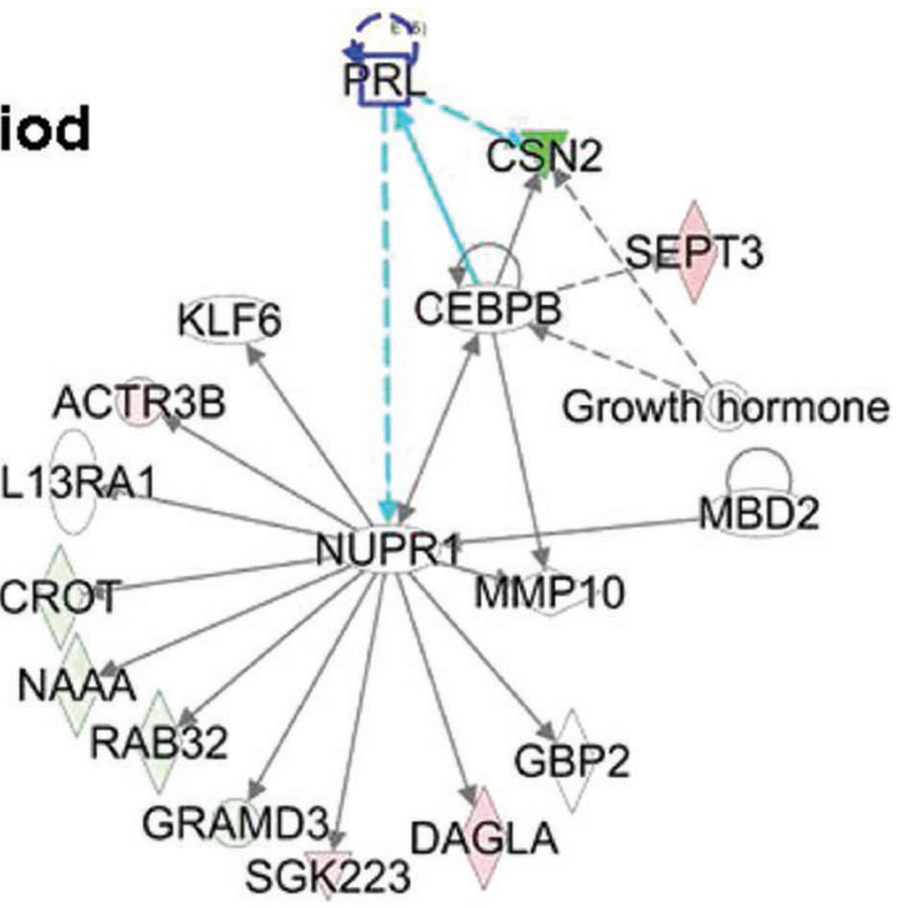

\section{Subsequent
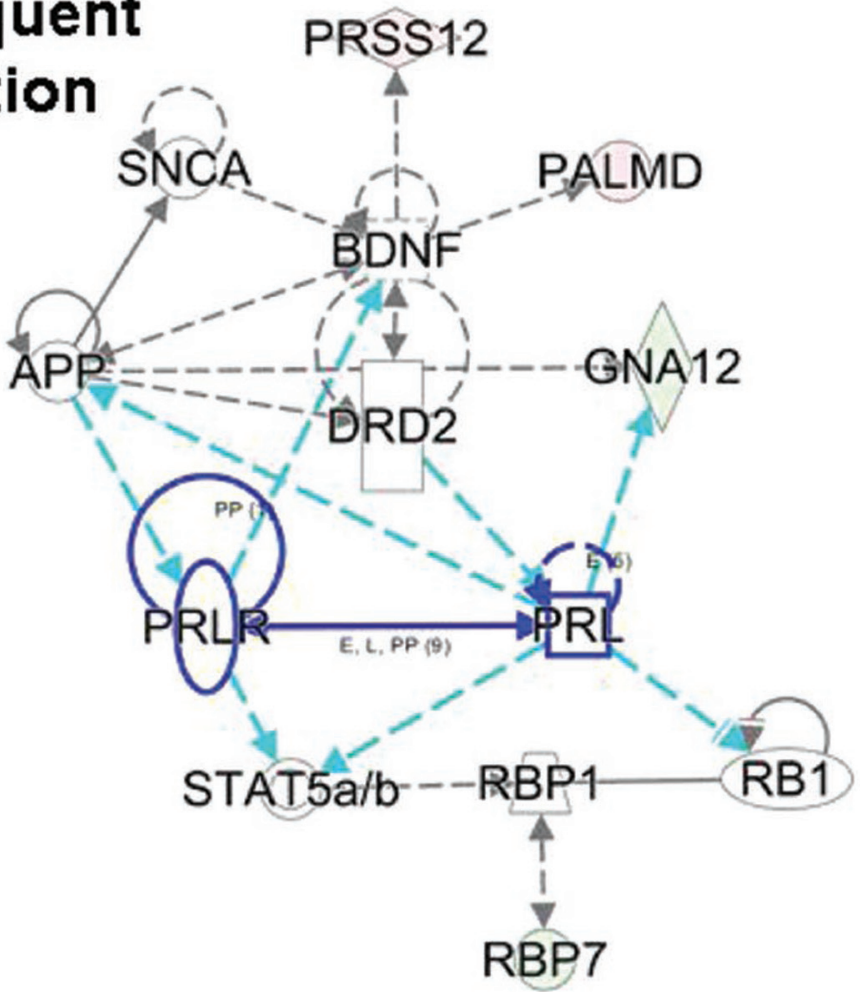

Figure 6. Potential mediation of treatment effects by prolactin (PRL) signaling. Networks [Ingenuity Pathway Analysis (IPA), Qiagen, Valencia, CA] involving transcripts whose abundance were similarly affected by bromocriptine and endophyte-infected fescue seed treatments during the dry period and the subsequent lactation are depicted. During the dry period, a functional regulatory network involving PRL was identified that affected reproductive system development and tissue development. During the subsequent lactation a functional regulatory network involving PRL and prolactin receptor was identified that affected cellular development, cell morphology, cellular assembly, and organization. Intensity of color reflects the magnitude of change, with green representing downregulation (relative to control) and red representing upregulation; blue coloring depicts inferred involvement of PRL. Gene abbreviations and biological functions are summarized in Appendix Table A2. 
the involvement of similar cell signaling pathways or mechanisms of action for both BROMO and INF, as well as the likely involvement of PRL messaging pathways. Bromocriptine may serve as an excellent model for better understanding the mechanism of action of ergot alkaloid intake during different phases of lactation and accompanying actions of PRL in the bovine mammary gland.

\section{ACKNOWLEDGMENTS}

The authors thank Donald Carbaugh and Dennis Hucht (Animal Genomics and Improvement Laboratory, USDA-ARS, Beltsville, MD) for their excellent assistance with tissue sampling, feed preparation and animal handling, and Mary Niland (Animal Genomics and Improvement Laboratory, USDA-ARS, Beltsville, MD) for technical assistance. We also thank personnel of the Beltsville Agricultural Research Center (Beltsville, MD), particularly Jonathan Leith and Mike Kemp, for help initiating the project and for managing cows throughout the study. This work was funded by Current Research Information Service project no. 1265-3200-083-00D from USDA Agricultural Research Service (Beltsville Agricultural Research Center), by National Research Initiative Competitive Grant no. 2008-35206-18825 from the USDA National Institute of Food and Agriculture (Beltsville Agricultural Research Center), and by University of Kentucky Agriculture Experiment Station (Manuscript No. 18-07-059).

\section{REFERENCES}

Aiken, G. E., and J. R. Strickland. 2013. Forages and pastures symposium: Managing the tall fescue-fungal endophyte symbiosis for optimum forage-animal production. J. Anim. Sci. 91:2369-2378.

Akers, R. M., D. E. Bauman, A. V. Capuco, G. T. Goodman, and H. A. Tucker. 1981a. Prolactin regulation of milk secretion and biochemical differentiation of mammary epithelial cells in periparturient cows. Endocrinology 109:23-30.

Akers, R. M., D. E. Bauman, G. T. Goodman, A. V. Capuco, and H. A. Tucker. 1981b. Prolactin regulation of cytological differentiation of mammary epithelial cells in periparturient cows. Endocrinology 109:31-40.

Auchtung, T. L., A. G. Rius, P. E. Kendall, T. B. McFadden, and G. E. Dahl. 2005. Effects of photoperiod during the dry period on prolactin, prolactin receptor, and milk production of dairy cows. J. Dairy Sci. 88:121-127.

Baldwin, R. L. 6th, A. V. Capuco, C. M. Evock-Clover, P. Grossi, R. K. Choudhary, E. S. Vanzant, T. H. Elsasser, G. Bertoni, E. Trevisi, G. E. Aiken, and K. R. McLeod. 2016. Consumption of endophyte-infected fescue seed during the dry period does not decrease milk production in the following lactation. J. Dairy Sci. 99:7574-7589.

Bernard, J. K., A. B. Chestnut, B. H. Erickson, and F. M. Kelly. 1993. Effects of prepartum consumption of endophyte-infected tall fescue on serum prolactin and subsequent milk production of Holstein cows. J. Dairy Sci. 76:1928-1933.
Brown, M. A., L. M. Tharel, A. H. Brown Jr., W. G. Jackson, and J. R. Miesner. 1993. Milk production in Brahman and Angus cows on endophyte-infected fescue and common bermudagrass. J. Anim. Sci. 71:1117-1122.

Capuco, A. V., E. E. Connor, and D. L. Wood. 2008. Regulation of mammary gland sensitivity to thyroid hormones during the transition from pregnancy to lactation. Exp. Biol. Med. (Maywood) 233:1309-1314.

Capuco, A. V.. S. Kahl, L. J. W. Jack, R. A. Aschenbrenner, H. Wallace, and J. O. Bishop. 1995. Thyroid hormones are necessary to increase milk production in response to treatment with somatotropin or prolactin. J. Dairy Sci. 88:78. (Abstr.)

Carter, J. M., G. E. Aiken, C. T. Dougherty, and F. N. Schrick. 2010 Steer responses to feeding soybean hulls and steroid implantation on toxic tall fescue pasture. J. Anim. Sci. 88:3759-3766.

Connor, E. E., M. J. Meyer, R. W. Li, M. E. Van Amburgh, Y. R Boisclair, and A. V. Capuco. 2007. Regulation of gene expression in the bovine mammary gland by ovarian steroids. J. Dairy Sci. 90(Suppl 1):E55-E65.

Crawford, H. M. D. E. Morin, E. H. Wall, T. B. McFadden, and G. E. Dahl. 2015. Evidence for a role of prolactin in mediating effects of photoperiod during the dry period. Animals (Basel) 5:803-820.

Farr, V. C., K. Stelwagen, L. R. Cate, A. J. Molenaar, T. B. McFadden, and S. R. Davis. 1996. An improved method for the routine biopsy of bovine mammary tissue. J. Dairy Sci. 79:543-549.

Fitzgerald, B. P., and F. J. Cunningham. 1982. Effects of metoclopramide and bromocriptine on prolactin secretion in the pregnant ewe. J. Endocrinol. 93:41-46.

Hale, S. A., A. V. Capuco, and R. A. Erdman. 2003. Milk yield and mammary growth effects due to increased milking frequency during early lactation. J. Dairy Sci. 86:2061-2071.

Hughes, K., and C. J. Watson. 2012. The spectrum of STAT functions in mammary gland development. JAK-STAT 1:151-158.

Krämer, A., J. Green, J. Pollard Jr., and S. Tubendreich. 2014. Causal analysis approaches in Ingenuity Pathway Analysis. Bioinformatics 30:523-530.

Leng, N., J. A. Dawson, J. A. Thomson, V. Ruotti, A. I. Rissman, B. M. G. Smits, J. D. Haag, M. N. Gould, R. M. Stewart, and C. Kendziorski. 2013. EBSeq: An empirical Bayes hierarchical model for inference in RNA-seq experiments. Bioinformatics 29:1035-1043. https://doi.org/10.1093/bioinformatics/btt087.

Li, B., and C. N. Dewey. 2011. RSEM: Accurate transcript quantification from RNA-Seq data with or without a reference genome. BMC Bioinformatics 12:323.

Li, C. J., R. W. Li, Y. H. Wang, and T. H. Elsasser. 2007. Pathway analysis identifies perturbation of genetic networks induced by butyrate in a bovine kidney epithelial cell line. Funct. Integr. Genomics 7:193-205.

Peters, C. W., K. N. Grigsby, C. G. Aldrich, J. A. Paterson, R. J. Lipsey, M. S. Kerley, and G. B. Garner. 1992. Performance, forage utilization, and ergovaline consumption by beef cows grazing endophyte fungus-infected tall fescue, endophyte fungus-free tall fescue, or orchardgrass pastures. J. Anim. Sci. 70:1550-1561.

Strickland, J. R., J. W. Oliver, and D. L. Cross. 1993. Fescue toxicosis and its impact on animal agriculture. Vet. Hum. Toxicol. 35:454-464.

Viollet, B., S. Horman, J. Leclerc, L. Lantier, M. Foretz, M. Billaud, S. Giri, and F. Andreelli. 2010. AMPK inhibition in health and disease. Crit. Rev. Biochem. Mol. Biol. 45:276-295.

Wall, E. H., T. L. Auchtung, G. E. Dahl, S. E. Ellis, and T. B. McFadden. 2005. Exposure to short day photoperiod during the dry period enhances mammary growth in dairy cows. J. Dairy Sci. 88:1994-2003.

Wu, S., R. W. Li, W. Li, and C. J. Li. 2012. Transcriptome characterization by RNA-seq unravels the mechanisms of butyrate-induced epigenomic regulation in bovine cells. PLoS One 7:e36940.

Yates, S. G., and R. G. Powell. 1988. Analysis of ergopeptine alkaloids in endophyte-infected tall fescue. J. Agric. Food Chem. 36:337-340. 
Table A1. Abbreviations and functions for genes in Figure $5^{1}$

\begin{tabular}{ll}
\hline Abbreviation & Name and function \\
\hline ACOX1 & Acyl-CoA oxidase 1: The protein encoded by this gene is the first enzyme of the fatty acid $\beta$-oxidation pathway, \\
which catalyzes the desaturation of acyl-CoA to 2-trans-enoyl-CoA. It donates electrons directly to molecular oxygen, \\
thereby producing hydrogen peroxide. Among its related pathways are estrogen receptor pathway and peroxisomal lipid \\
metabolism. \\
1-acylglycerol-3-phosphate O-acyltransferase 2: The protein is located within the endoplasmic reticulum membrane and \\
converts lysophosphatidic acid to phosphatidic acid, the second step in de novo phospholipid biosynthesis. \\
Aryl hydrocarbon receptor: Ligand-activated transcriptional activator. Binds to the XRE promoter region of genes it \\
activates. Activates the expression of multiple phase I and II xenobiotic chemical metabolizing enzyme genes (such \\
as the CYP1A1 gene). Mediates biochemical and toxic effects of halogenated aromatic hydrocarbons. Involved in cell- \\
cycle regulation. Likely to play an important role in the development and maturation of many tissues. Regulates the \\
circadian clock by inhibiting the basal and circadian expression of the core circadian component PER1. Inhibits PER1 \\
by repressing the CLOCK-ARNTL/BMAL1 heterodimer mediated transcriptional activation of PER1.
\end{tabular}

Alpha catenin The catenin family of proteins play an important role in cell adhesion by connecting cadherins located on the plasma membrane to actin filaments inside the cell.

BTNL2

$C B X 5$ Butyrophilin-like 2: Negative regulator of T-cell proliferation.

Chromobox 5: Component of heterochromatin that recognizes and binds histone H3 tails methylated at Lys-9 (H3K9me), leading to epigenetic repression. In contrast, it is excluded from chromatin when Tyr-41 of histone H3 is phosphorylated (H3Y41ph). Can interact with lamin-B receptor (LBR). This interaction can contribute to the association of the heterochromatin with the inner nuclear membrane. Involved in the formation of functional kinetochore through interaction with MIS12 complex proteins.

CEBPA CCAAT/enhancer binding protein alpha: This intron-less gene encodes a transcription factor that contains a basic leucine zipper (bZIP) domain and recognizes the CCAAT motif in the promoters of target genes. The encoded protein functions in homodimers and heterodimers with CCAAT/enhancer-binding proteins $\beta$ and gamma. Activity of this protein can modulate the expression of genes involved in cell cycle regulation as well as in BW homeostasis.

$C E B P B$ CCAAT/enhancer binding protein beta: The encoded protein functions as a homodimer but can also form heterodimers with CCAAT/enhancer-binding proteins $\alpha$, delta, and gamma. Activity of this protein is important in the regulation of genes involved in immune and inflammatory responses, among other processes.

CNR1 Canabinoid receptor 1: G-protein coupled receptor for endogenous cannabinoids (eCB), including N-arachidonoyl ethanolamide (also called anandamide or AEA) and 2-arachidonoylglycerol (2-AG), as well as phytocannabinoids, such as delta(9)-tetrahydrocannabinol (THC).

CTNNB1 Catenin beta 1: The protein encoded by this gene is part of a complex of proteins that constitute adherens junctions $(\mathrm{AJ})$; AJ are necessary for the creation and maintenance of epithelial cell layers by regulating cell growth and adhesion between cells.

ERK

Alias for MAPK1, mitogen-activated protein kinase 1: Extracellular signal-regulated kinases are a group of mitogenactivated protein kinases (MAPK) that mediate intracellular signaling. ERK1 and ERK2 (MAPK3 and MAPK1) transduce signals from growth factors and phorbol esters. They are expressed in all tissues at varying levels.

ESR2 Estrogen receptor 2 (ER Beta): Binds estrogens with an affinity similar to that of ESR1 and activates expression of reporter genes containing estrogen response elements (ERE) in an estrogen-dependent manner.

EZH2 Enhancer Of zeste 2 polycomb repressive complex 2 subunit: This gene encodes a member of the polycomb-group (PcG) family. PcG family members form multimeric protein complexes, which are involved in maintaining the transcriptional repressive state of genes over successive cell generations. Catalytic subunit of the PRC2/EED-EZH2 complex, which methylates Lys-9 (H3K9me) and Lys-27 (H3K27me) of histone H3, leading to transcriptional repression of the affected target gene.

FGF2 Fibroblast growth factor 2: Plays an important role in the regulation of cell survival, cell division, angiogenesis, cell differentiation, and cell migration. Functions as potent mitogen in vitro, can induce angiogenesis.

FOXA1 Forkhead box A1: Transcription factor that is involved in embryonic development, establishment of tissue-specific gene expression, and regulation of gene expression in differentiated tissues. Is thought to act as a pioneer factor opening the compacted chromatin for other proteins through interactions with nucleosomal core histones and thereby replacing linker histones at target enhancer or promoter sites. Modulates the transcriptional activity of nuclear hormone receptors. Is involved in ESR1-mediated transcription; required for ESR1 binding to the NKX2-1 promoter in breast cancer cells; binds to the RPRM promoter and is required for the estrogen-induced repression of RPRM. Involved in regulation of apoptosis by inhibiting the expression of BCL2. Involved in cell cycle regulation by activating expression of CDKN1B, alone or in conjunction with BRCA1.

FOXL2 Forkhead box L2: This gene encodes a forkhead transcription factor. The protein contains a forkhead DNA binding domain and may play a role in ovarian development and function. Expansion of a polyalanine repeat region and other mutations in this gene are a cause of blepharophimosis syndrome and premature ovarian failure 3.

GATA4 GATA binding protein 4: This gene encodes a member of the GATA family of zinc-finger transcription factors. Members of this family recognize the GATA motif, which is present in the promoters of many genes. This protein is thought to regulate genes involved in embryogenesis and in myocardial differentiation and function, and is necessary for normal testicular development.

HNF1A

HNF1 homeobox A: Transcriptional activator that regulates the tissue specific expression of multiple genes, especially in pancreatic islet cells and in liver. Required for the expression of several liver specific genes. Binds to the inverted palindrome 5-GTTAATNATTAAC-3. 
Table A1 (Continued). Abbreviations and functions for genes in Figure $5^{1}$

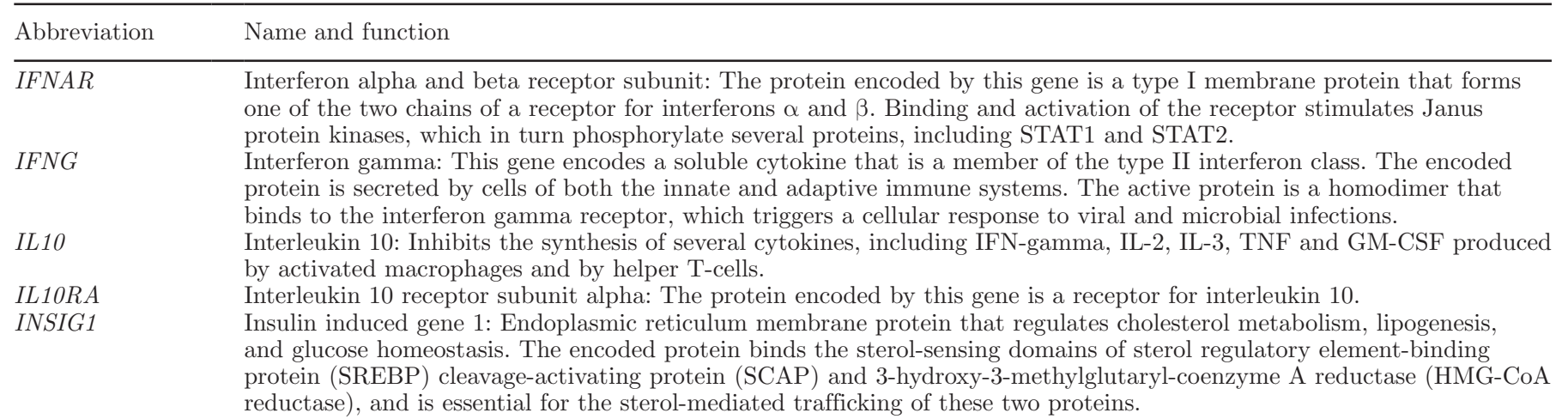

IRS1 Insulin receptor substrate 1: May mediate the control of various cellular processes by insulin. When phosphorylated by the insulin receptor binds specifically to various cellular proteins containing SH2 domains such as phosphatidylinositol 3-kinase p85 subunit or GRB2.

IRS2 Insulin receptor substrate 2: This gene encodes the insulin receptor substrate 2, a cytoplasmic signaling molecule that mediates effects of insulin, insulin-like growth factor 1, and other cytokines by acting as a molecular adaptor between diverse receptor tyrosine kinases and downstream effectors.

KLF1S Kruppel-like factor 1: This gene encodes a hematopoietic-specific transcription factor that induces high-level expression of adult $\beta$-globin and other erythroid genes.

KMT2D Lysine methyltransferase 2D: Histone methyltransferase. Methylates Lys-4 of histone H3 (H3K4me). H3K4me represents a specific tag for epigenetic transcriptional activation. Acts as a coactivator for estrogen receptor by being recruited by ESR1, thereby activating transcription.

LIPE Lipase E, hormone sensitive type: The protein encoded by this gene has a long and a short form, generated by use of alternative translational start codons. The long form is expressed in steroidogenic tissues such as testis, where it converts cholesteryl esters to free cholesterol for steroid hormone production. The short form is expressed in adipose tissue, among others, where it hydrolyzes stored triglycerides to free fatty acids.

MYOCD Myocardin: This gene encodes a nuclear protein, which is expressed in heart, aorta, and in smooth muscle cell-containing tissues. It functions as a transcriptional co-activator of serum response factor (SRF) and modulates expression of cardiac and smooth muscle-specific SRF-target genes, and thus may play a crucial role in cardiogenesis and differentiation of the smooth muscle cell lineage

NFKB1 Nuclear factor kappa B subunit 1: NF-kappa-B is a pleiotropic transcription factor present in almost all cell types and is the endpoint of a series of signal transduction events that are initiated by a vast array of stimuli related to many biological processes such as inflammation, immunity, differentiation, cell growth, tumorigenesis and apoptosis.

NR3C2 Nuclear receptor subfamily 3 group C member 2: Receptor for both mineralocorticoids (MC) such as aldosterone and glucocorticoids (GC) such as corticosterone or cortisol. Binds to mineralocorticoid response elements (MRE) and transactivates target genes.

P38 MAPK Mitogen-activated protein kinase 14 (P38 mitogen activated protein kinase): This kinase is activated by various environmental stresses and proinflammatory cytokines. The activation requires its phosphorylation by MAP kinase kinases (MKK), or its autophosphorylation triggered by the interaction of MAP3K7IP1/TAB1 protein with this kinase. The substrates of this kinase include transcription regulator ATF2, MEF2C, and MAX, cell cycle regulator CDC25B, and tumor suppressor p53, which suggest the roles of this kinase in stress related transcription and cell cycle regulation, as well as in genotoxic stress response.

PI3K Phosphatidylinositol-4,5-bisphosphate 3-kinase: PI 3-Kinases (phosphoinositide 3-kinases, PI 3-Ks) are a family of lipid kinases capable of phosphorylating the $3^{\prime} \mathrm{OH}$ of the inositol ring of phosphoinositides.

PPARA Peroxisome proliferator activated receptor alpha: Ligand-activated transcription factor. Key regulator of lipid metabolism. Activated by the endogenous ligand 1-palmitoyl-2-oleoyl-sn-glycerol-3-phosphocholine (16:0/18:1-GPC). Activated by oleoylethanolamide, a naturally occurring lipid that regulates satiety. Receptor for peroxisome proliferators such as hypolipidemic drugs and fatty acids. Regulates the peroxisomal $\beta$-oxidation pathway of fatty acids. Functions as transcription activator for the ACOX1 and P450 genes. Transactivation activity requires heterodimerization with RXRA and is antagonized by $\mathrm{NR} 2 \mathrm{C} 2$.

PPARG Peroxisome proliferator activated receptor gamma: This gene encodes a member of the peroxisome proliferator-activated receptor (PPAR) subfamily of nuclear receptors. PPAR form heterodimers with retinoid X receptors (RXR) and these heterodimers regulate transcription of various genes. Three subtypes of PPAR are known: PPAR- $\alpha$, PPAR-delta, and PPAR-gamma. The protein encoded by this gene is PPAR-gamma and is a regulator of adipocyte differentiation.

PTGS2 Prostaglandin-endoperoxide synthase 2: Cyclooxygenase (also known as COX, prostaglandin-endoperoxide synthase, prostaglandin G/H synthase) is expressed in cells in three isoforms. COX-1 (constitutive) and COX-2 (inducible) isoforms catalyze the rate-limiting step of prostaglandin production. PTGS2 is a key step in the production of prostaglandin E2 (PGE2), which plays important roles in modulating motility, proliferation, and resistance to apoptosis.

RARRES2 Retinoic acid receptor responder 2: Secreted chemotactic protein that initiates chemotaxis via the ChemR23 G proteincoupled seven-transmembrane domain ligand. Expression of this gene is upregulated by the synthetic retinoid tazarotene and occurs in a wide variety of tissues.

S100A8 S100 calcium binding protein A8: The protein encoded by this gene is a member of the S100 family of proteins containing 2 EF-hand calcium-binding motifs. S100 proteins are localized in the cytoplasm or nucleus of a wide range of cells, and involved in the regulation of several cellular processes such as cell cycle progression and differentiation. 
Table A1 (Continued). Abbreviations and functions for genes in Figure $5^{1}$

\begin{tabular}{|c|c|}
\hline Abbreviation & Name and function \\
\hline$S C D$ & $\begin{array}{l}\text { Stearoyl-CoA desaturase: This gene encodes an enzyme involved in fatty acid biosynthesis, primarily the synthesis of } \\
\text { oleic acid. The protein belongs to the fatty acid desaturase family and is an integral membrane protein located in the } \\
\text { endoplasmic reticulum. }\end{array}$ \\
\hline SREBF1 & $\begin{array}{l}\text { Sterol regulatory element binding transcription factor } 1 \text { : Transcriptional activator required for lipid homeostasis. } \\
\text { Regulates transcription of the LDL receptor gene as well as the fatty acid and to a lesser degree the cholesterol synthesis } \\
\text { pathway }\end{array}$ \\
\hline SREBF2 & $\begin{array}{l}\text { Sterol regulatory element binding transcription factor } 2 \text { : Transcriptional activator required for lipid homeostasis. } \\
\text { Regulates transcription of the LDL receptor gene as well as the cholesterol and to a lesser degree the fatty acid synthesis } \\
\text { pathway. Binds the sterol regulatory element } 1 \text { (SRE-1) (5-ATCACCCCAC-3) found in the flanking region of the LDRL }\end{array}$ \\
\hline
\end{tabular}
factors. This protein binds to the serum response element (SRE) in the promoter region of target genes. This protein regulates the activity of many immediate-early genes, for example c-fos, and thereby participates in cell cycle regulation, apoptosis, cell growth, and cell differentiation.

STAT3 Signal transducer and activator of transcription 3: STAT (signal transducers and activators of transcription) are a family of seven transcription factors that form part of the JAK-STAT signaling cascade, the basis of the signal transduction mechanism for many cytokine receptors. STAT are activated by phosphorylation by JAK. (STAT3 and STAT5 have reciprocal patterns of activation in mammary gland, with STAT5 appearing to serve as a cell survival factor and STAT3 as a cell death factor for mammary epithelium.)

TGM2 Transglutaminase 2: Catalyzes the cross-linking of proteins and the conjugation of polyamines to proteins.

THRB Thyroid hormone receptor beta: The protein encoded by this gene is a nuclear hormone receptor for triiodothyronine. It is one of the several receptors for thyroid hormone, and has been shown to mediate the biological activities of thyroid hormone.

TLR4 Toll-like receptor 4: The protein encoded by this gene is a member of the Toll-like receptor (TLR) family, which plays a fundamental role in pathogen recognition and activation of innate immunity.

TLR9 Toll-like receptor 9: The protein encoded by this gene is a member of the Toll-like receptor (TLR) family, which plays a fundamental role in pathogen recognition and activation of innate immunity.

TNFRSF18 TNF receptor superfamily member 18: Receptor for TNFSF18. Seems to be involved in interactions between activated T-lymphocytes and endothelial cells and in the regulation of T-cell receptor-mediated cell death. Mediated NF-kappa-B activation via the TRAF2/NIK pathway.

TNFRSF1A TNF receptor superfamily member 1A: Receptor for TNFSF2/TNF- $\alpha$ and homotrimeric TNFSF1/lymphotoxin- $\alpha$. The adapter molecule FADD recruits caspase-8 to the activated receptor. The resulting death-inducing signaling complex (DISC) performs caspase-8 proteolytic activation which initiates the subsequent cascade of caspases (aspartate-specific cysteine proteases) mediating apoptosis

TREM1 Triggering receptor expressed on myeloid cells: Stimulates neutrophil and monocyte-mediated inflammatory responses. Triggers release of pro-inflammatory chemokines and cytokines, as well as increased surface expression of cell activation markers. Amplifier of inflammatory responses that are triggered by bacterial and fungal infections and is a crucial mediator of septic shock.

TRIM24 Tripartite motif containing 24: The protein encoded by this gene mediates transcriptional control by interaction with the activation function 2 (AF2) region of several nuclear receptors, including the estrogen, retinoic acid, and vitamin $\mathrm{D}_{3}$ receptors.

VDR Vitamin D receptor: Nuclear hormone receptor for vitamin $\mathrm{D}_{3}$. Downstream targets of this nuclear hormone receptor are principally involved in mineral metabolism though the receptor regulates a variety of other metabolic pathways, such as those involved in the immune response and cancer.

XBP1 X-box binding protein: Functions as a transcription factor during endoplasmic reticulum (ER) stress by regulating the unfolded protein response (UPR). Required for cardiac myogenesis and hepatogenesis during embryonic development, and the development of secretory tissues such as exocrine pancreas and salivary gland

${ }^{1}$ Gene functions are derived from GeneCards (https://www.genecards.org/). 
Table A2. Abbreviations and functions for genes in Figure $6^{1}$

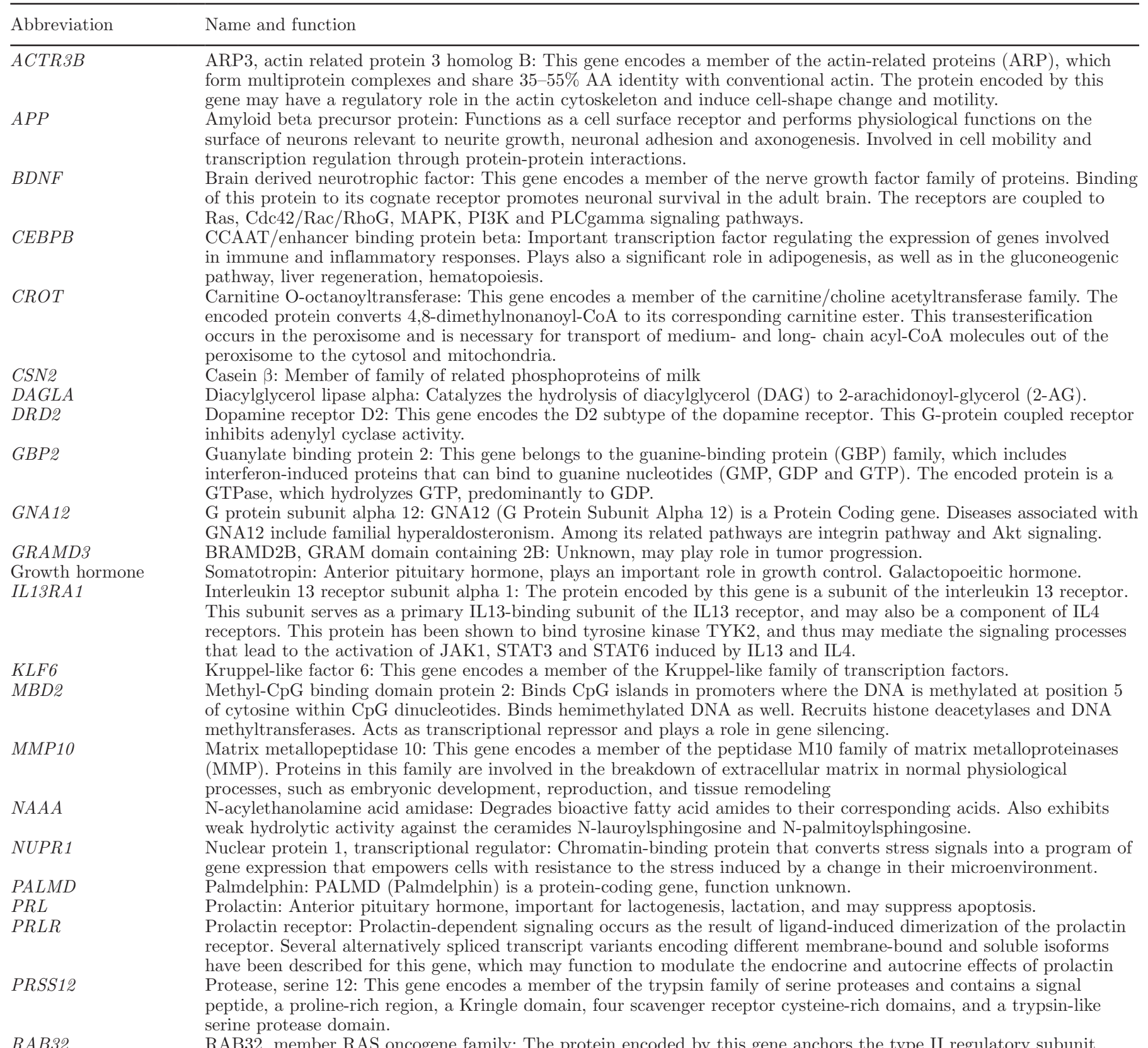

RAB32, member RAS oncogene family: The protein encoded by this gene anchors the type II regulatory subunit of protein kinase A to the mitochondrion and aids in mitochondrial fission. The encoded protein also appears to be involved in autophagy and melanosome secretion.

$R B 1$ $\mathrm{RB}$ transcriptional corepressor 1: The protein encoded by this gene is a negative regulator of the cell cycle and was the first tumor suppressor gene found. The encoded protein also stabilizes constitutive heterochromatin to maintain the overall chromatin structure.

RBP1 Retinol binding protein 1: This gene encodes the carrier protein involved in the transport of retinol. Cytoplasmic retinol-binding protein. Accepts retinol from the transport protein STRA6, and thereby contributes to retinol uptake, storage and retinoid homeostasis

RBP7 Retinol binding protein 7: The protein encoded by this gene is a member of the cellular retinol-binding protein (CRBP) family, whose members are required for vitamin A stability and metabolism. Intracellular transport of retinol. protein kinase family. A similar protein in rat binds to Rho family GTPase 2 (Rnd2) and regulates neurite outgrowth via activation of Ras homolog gene family, member A (RhoA). 
Table A2 (Continued). Abbreviations and functions for genes in Figure $6^{1}$

\begin{tabular}{ll}
\hline Abbreviation & Name and function \\
\hline$S N C A$ & $\begin{array}{l}\text { Synuclein alpha: Alpha-synuclein is a member of the synuclein family, which also includes } \beta \text { - and gamma-synuclein. } \\
\text { May be involved in the regulation of dopamine release and transport. } \\
\text { Signal transducer and activator of transcription 5A/5B: The protein is a member of the STAT family of transcription } \\
\text { factors. In response to cytokines and growth factors, STAT family members are phosphorylated by the receptor- } \\
\text { associated kinases, and then form homo- or heterodimers that translocate to the cell nucleus where they act as } \\
\text { transcription activators. STAT5A is a regulator of milk protein gene expression and is essential for mammary } \\
\text { development and lactogenesis. [STAT5A is necessary for formation of luminal progenitor cells, differentiation of milk } \\
\text { producing alveolar cells during pregnancy.] }\end{array}$
\end{tabular}

${ }^{1}$ Gene functions are derived from GeneCards (https://www.genecards.org/). 